\title{
Pengembangan Desain Endoscope Portable dengan Pendekatan Aktivitas Endoscope Tower dan Komponen pada Produk Sejenis
}

\author{
Hamasah Dinillah, Djoko Kuswanto, dan Taufik Hidayat \\ Departemen Desain Produk, Fakultas Arsitektur Desain dan Perencanaan, \\ Institut Teknologi Sepuluh Nopember (ITS) \\ e-mail:zota@prodes.its.ac.id
}

\begin{abstract}
Abstrak-Pemeriksaan menggunakan alat endoscope dibidang THTKL sangan membantu viusalisasi bagian dalam organ yang ditarget. Di Indonesia alat endoscope yang tersedia berbentuk tower dengan dimensi yang relatif besar, sebesar lemari pakaian satu pintu. Perangkat endoscope model tower terdiri dari teleskop, layar monitor, sumber cahaya, kamera dan memori penyimpanan. Banyak penelitian yang mengembangkan pembuatan endoscope portable, saat ini produk endoscope portable yang dihasilkan dapat mengakomodasi dimensi smartphone dengan ukuran diagonal 5"-5.5" dengan letak kamera di bagian tengah dan samping kiri dengan hasil gambar atau video yang bergantung pada kualitas kamera pada smartphone. Dalam mendesain alat endoscope portable ini dilakukan shadowing terhadap perilaku penggunaan pada endoscope tower dan melihat kebutuhan komponen dari bencharking produk sejenis. Didapatkan hasil desain dapat mencakup lebar smartphone hingga $95 \mathrm{~mm}$ dengan hanya membutuhkan 2 step peamsangan.
\end{abstract}

Kata Kunci-Endoscope, Portable, Smartphone.

\section{PENDAHULUAN}

$\mathrm{K}$ EADAAN lembaga kesehatan di Indonesia dengan jumlah rumah sakit pada tahun 2016 berjumlah 2.601 dan 555 Rumah Sakit Khusus (RSK). Terdapat 2,42\% RS Kelas A, 14,11\% Kelas B, 41,25\% RS Kelas C, 21,07\% RS Kelas D, dan $21,15 \%$ RS lainnya belum ditetapkan kelas kemudian jumlah puskesmas sampai dengan Desember 2016 adalah 9.767 unit [1]. Dalam hal ini lembaga kesehatan di Indonesia belum mampu memfasilitasi pelayanan pemeriksaan endoscope. Keadaan geografis Indonesia yang berupa gugusan pulau juga menjadi faktor penyebab terbatasnya masyarakat Indonesia untuk melakukan pemeriksaan THTKL di pusatpusat kota.

Pemeriksaan menggunakan endoscope dibidang THTKL sangat membantu dokter spesialis THTKL untuk melihat lebih detail dan jelas sehingga dapat meningkatkan kemampuan diagnosis suatu penyakit [2]. Walaupun sudah tersedia alat perekam dengan kualitas baik (video resolusi tinggi) yang mendukung dokter spesialis THTKL, tetapi endoscope model tower menjadi barang dengan harga yang tidak terjangkau dan ketersediaan yang terbatas melihat kondisi lembaga kesehatan di Indonesia [3].

Dari permasalahan di atas, muncul beberapa penelitian di dunia tentang endoscope portable portable [4],[5],[6],[7] dan [8]. Perangkat endoscope dengan menggunakan smartphone sebagai pengganti $P C$ tower pada endoscope yang telah digunakan sebelumnya agar bisa mengakses fasilitas endoscope dengan lebih murah.

Namun dewasa ini penelitian tentang endoscope portable masih terbatas membahas komparasi hasil video atau gambar yang dihasilkan antara endoscope portable dan endoscope tower sedangkan untuk pembuatan alat endoscope portable sendiri masih belum ada, sehingga pembuatan alat endoscope portable belum diproduksi di Indonesia maupun banyak negara lainnya.

Maka dari itu penulis bertujuan untuk melakukan penelitian tentang langkah-langkah dan apa saja yang perlu diperhatikan dalam mendesain dan memproduksi endoscope portable.

\section{METODE PENELITIAN}

\section{A. Observasi}

Metode observasi digunakan untuk mengetahui, mendapatkan, serta mengumpulkan data dengan mendatangi sumber secara langsung. Adapun hasil yang didapatkan yaitu berupa foto, rekaman suara/gambar (voice recorder atau video recorder), catatan, dsb. Metode ini diperlukan untuk melihat aktivitas apa saja yang dilakukan oleh dokter atau tenaga medis yang mengoperasikan alat endoscope tower. Observasi dilakukan di RS Unair Surabaya pada tanggal 9 Maret 2018, sejak pukul 14.00 hingga 14.35 degan dr. Tri Hedianto.

\section{B. Studi Produk Sejenis}

Mengumpulkan data produk sejenis yang sudah ada di pasaran, dan akan di kembangkan kembali (redesign) sesuai dengan kebutuhan dan masalah. Produk sejenis dijadikan sebagai dasar produk dalam mendesain. Dalam proses desainnya perlu memperhatikan dan menganalisa produk sejenis sehingga ditemukan solusi dan kebutuhan dari permaslaahan yang ada, namun tetap tidak melupakan hal-hal mendasar yang harus tetap ada dalam produk sejenis tersebut.

\section{Studi Produk Smartphone}

Studi produk smartphone yang ada di pasaran diperlukan untuk mendapatkan data dimensi smartphone dan letak kamera pada smartphone yang berpengaruh pada peletakan lensa telescope.

\section{Analisis Kebutuhan}

Analisis kebutuhan dilakukan dengan menarik kesimpulan dari hasil observasi dan studi produk sejenis untuk mengetahui komponen-komponen yang dibutuhkan pada alat endoscope portable dan menyesuaikan dengan tahapan dan kebiasaan 
atau perilaku pemeriksaan yang telah dilakukan pada alat sebelumnya.

\section{E. Pengembangan Desain}

Metode pengembangan desain Metode pengembangan desain yaitu metode yang digunakan untuk menemukan ideide, solusi berupa gambaran produk secara dua atau tiga dimensi beserta bentuk, operasional dan ukurannya.

\section{HASIL DAN PEMBAHASAN}

\section{A. Analisis Aktivitas}

Tabel 1.

Aktivitas penggunaan endoscope

\begin{tabular}{|c|c|c|c|c|}
\hline $\mathrm{No}$ & Indikator & Tower & Portable & Gambar \\
\hline 1 & $\begin{array}{l}\text { Memakai } \\
\text { sarung tangan }\end{array}$ & V & V & \\
\hline 2 & $\begin{array}{l}\text { Menyalakan } \\
\text { power utama } \\
\text { endoscope }\end{array}$ & $\mathrm{V}$ & X & \\
\hline 3 & $\begin{array}{l}\text { Menyalakan } \\
\text { perangkat } \\
\text { rekam }\end{array}$ & V & X & \\
\hline 4 & $\begin{array}{l}\text { Mengambil } \\
\text { perangkat } \\
\text { kamera untuk } \\
\text { visualisasi }\end{array}$ & V & X & \\
\hline 5 & $\begin{array}{l}\text { Memasang } \\
\text { smartphone } \\
\text { pada konektor }\end{array}$ & $\mathrm{X}$ & V & \\
\hline 6 & $\begin{array}{l}\text { Mengambil } \\
\text { lightsource dan } \\
\text { telescope }\end{array}$ & V & V & \\
\hline 7 & $\begin{array}{l}\text { Memasang } \\
\text { lightsource } \\
\text { pada kamera }\end{array}$ & $\mathrm{V}$ & V & \\
\hline 8 & $\begin{array}{l}\text { Menyalakan } \\
\text { lightsource } \\
\text { pada }\end{array}$ & V & $\mathrm{V}$ & \\
\hline 9 & $\begin{array}{l}\text { Mengatur } \\
\text { intensitas } \\
\text { lightsource }\end{array}$ & $\mathrm{V}$ & $\mathrm{X}$ & \\
\hline 10 & $\begin{array}{l}\text { Memasang } \\
\text { telescope pada } \\
\text { coupler }\end{array}$ & $\mathrm{V}$ & V & \\
\hline 11 & $\begin{array}{l}\text { Melakukan } \\
\text { pengaturan } \\
\text { pada kamera }\end{array}$ & V & V & \\
\hline
\end{tabular}

\begin{tabular}{llccc}
\hline \hline No & Indikator & Tower & Portable & Gambar \\
\hline 12 & $\begin{array}{l}\text { Melakukan } \\
\text { pengaturan } \\
\text { white balance }\end{array}$ & $\mathrm{V}$ & $\mathrm{X}$ & \\
13 & Mengatur & $\mathrm{V}$ & $\mathrm{X}$ & \\
& White Balance & & \\
& dengan kapas \\
& sebagai acuan \\
& warna putih \\
& terbaik
\end{tabular}

14

Mengambil alat untuk

melakukan

tindakan.

15 Melakukan pemeriksaan ke dalam hidung

16 Melakukan pemeriksaan dengan tindakan

17 Melepas telescope dan lightsource

18 Melepas telescope dari lightsource

19 Mematikan lightsource

20 Meletakan peralatan yang telah digunakan disterilisasi oleh perawat

21 Mengambil

data dari perangkat recoder

22 Transfer data ke komputer

23 Membaca rekaman foto maupun video untuk dianalisa

24 Membaca hasil rekam diagnosa dan mengirimkanny a kepada pasien.

25 Mematikan perangkat endoscope

Analisis aktivitas diatas didapatkan bahwa pada produk endoscope portable dan endoscope tower memliki kesamaan tahapan yaitu pada tahapan:

1. Memakai sarung tangan

2. Mengambil dan memasang lightsource pada kamera

3. Menyalakan lightsource

4. Memasang telescope pada coupler

5. Mengatur perbesaran/zoom pada kamera

6. Mengambil alat untuk melakukan tindakan

7. Melakukan pemeriksaan ke dalam hidung

8. Melakukan pemeriksaan dengan tindakan

9. Melepas telescope dan lightsource

10. Mematikan lightsource

11. Meletakan peralatan yang telah digunakan disterilisasi oleh perawat 
12. Membaca hasil rekam diagnosa dan mengirimkannya kepada pasien.

\section{B. Studi dan Analisis Produk Sejenis}

Tabel 2

Endoscope berbasis smartphone yang ada dispasaran [6]

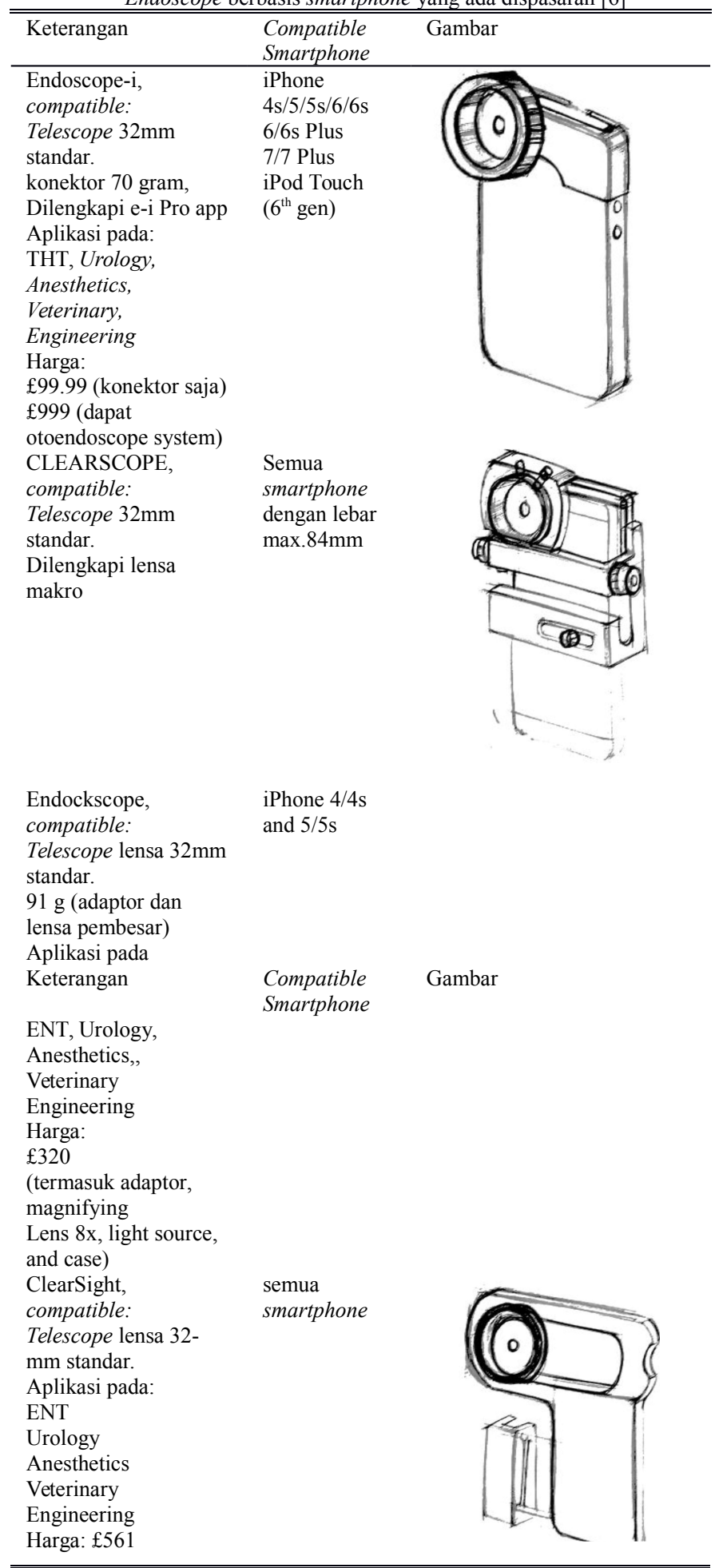

Produk endoscope portable sejenis memiliki komponen utama yaitu,

1. Coupler (untuk memasang lensa telescope)

\section{Holder penjepit smartphone}

\section{Studi dan Analisis Produk Smartphone}

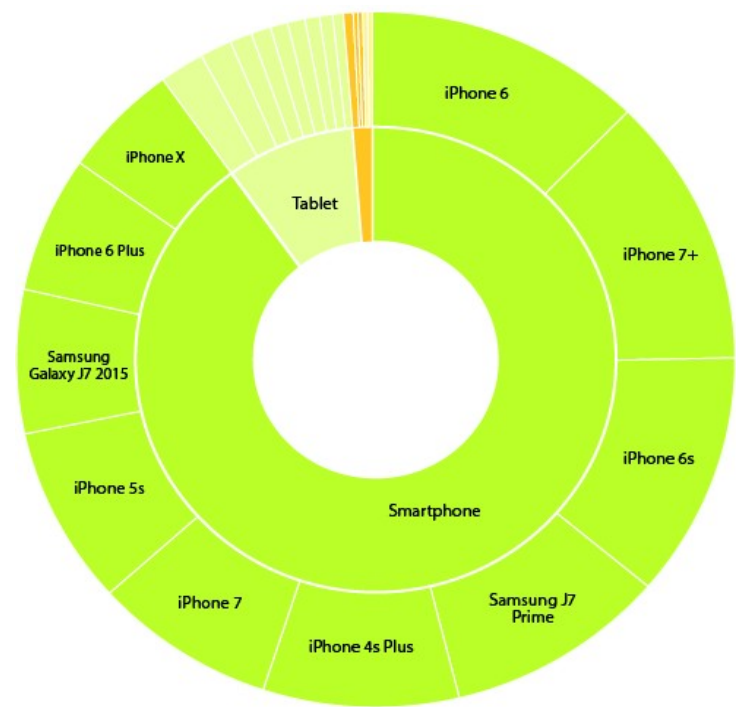

Gambar 1. Tren produk smartphone \& tablet di Asia 2017 diadaptasi dari .

Menurut survey yang telah dilakukan penelitian sebelumnya oleh Scientia Mobile menunjukkan bahwa ukuran layar smartphone yang lebih besar telah mendominasi pasar dengan rincian jenis smartphone paling mendominasi. Ukuran layar diagonal 5,5 sampai 6 inci adalah segmen yang paling populer, dengan $43,3 \%$ pada 2017 . Kemudian dari semua jenis smartphone yang beredar dipasaran pada Gambar 1 kamera smartphone hanya terletak pada bagian tengah smartphone atau bagian kiri atas smartphone.

\section{Analisis Kebutuhan}

Berdasar studi aktivtias, produk endoscope portable sejenis dan produk smartphone yang beredar di pasaran dalam mendesain sebuah endoscope portable dibutuhkan.

1. Komponen Utama
a. Coupler
b. Smartphone holder/penjepit

2. Peralatan pendukung
a. Lightsource portable
b. Smartphone

Hal yang perlu diperhatikan dalam mendesain endoscope portable adalah

1. Letak kamera pada smartphone

2. Dimensi smartphone

\section{E. Pengembangan Desain}

Pengembangan desain dilakukan dengan berbagai secara dua dimensi maupun tiga dimensi adapun eksplorasi desain yang telah dilakukan sebagai berikut.

\section{1) Eksplorasi desain 1}

Arah gerak penjepit 1 axis (sumbu $\mathrm{x}$ ), arah gerak coupler 1 axis (sumbu $\mathrm{x}$ ) menggunakan mekanisme gotri dengan bola besi. Pengaman smartphone berada pada 2 sisi (kiri dan kanan). 


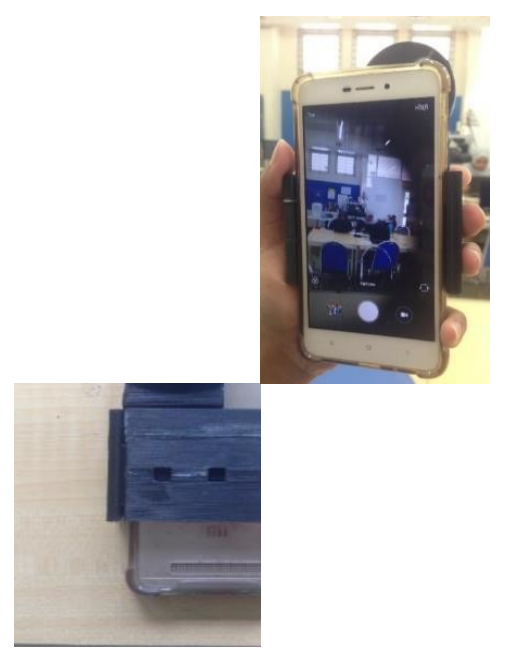

Gambar 2. Eksplorasi desain 1.

Kelebihan:

a. Coupler dapat di adjust pada 1 axis

b. Mekanisme penjepit pada konektor sederhana dan fit pada ukuran smartphone.

c. Jarak coupler dan lensa kamera smartphone hanya memiliki jarak $3 \mathrm{~mm}$.

Kekurangan:

a. Penjepit smartphone hanya di tentukan untuk ukuran smartphone 5, 5.5, dan 6 inci

b. Penjepit hanya dapat diadjust 1 axis (sumbu $\mathrm{x}$ )

c. Mekanisme enjepit tidak mencengkram dengan kuat sehingga ada kekhawatiran smartphone terjatuh

d. Coupler tidak dapat menjangkau kamera yang berada disisi kiri.

2) Eksplorasi desain 2

Penjepit smartphone berada pada 2 sisi (kiri dan kanan), penjepit pada sisi kanan dapat didorong dan ditarik sesuai kebutuhan ukuran smartphone, menggunakan mekanisme gerigi sehigga dapat langsung mengunci posisi penjepit.

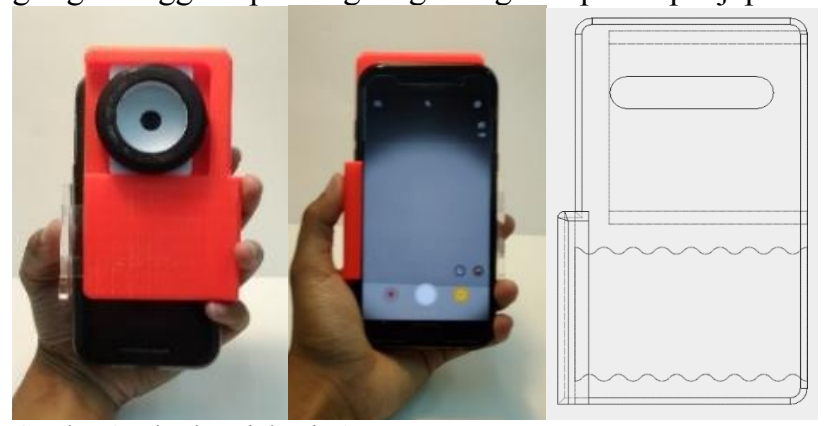

Gambar 3. Eksplorasi desain 2.

Kelebihan:

a. Mekanisme penjepit sederhana sehingga mudah di operasikan.

b. Memiliki mekanisme kuncian berbentuk gelombang untuk mengunci posisi penjepit.

c. Penyesuaian posisi coupler dapat lebih presisi karena mekanisme sliding.

Kekurangan: a. Bentuk penjepit berbentuk datar sehingga tidak dapat mencengkram smartphone.

b. Sisi penjepit yang dapat ditarik berada pada sisi kanan sehingga ada kemungkinan terlepas ketika pemakaian landscape karena posisi coupler harus mendekati organ yang di periksa.

c. Bentuk penjepit membatasi ukuran smartphone yang dapat masuk hanya smartphone dengan tebal $8 \mathrm{~mm}$.

d. Mekanisme kuncian pada penjepit tidak mencengkram dengan kencang sehingga ada resiko smartphone jatuh

3) Eksplorasi desain 3

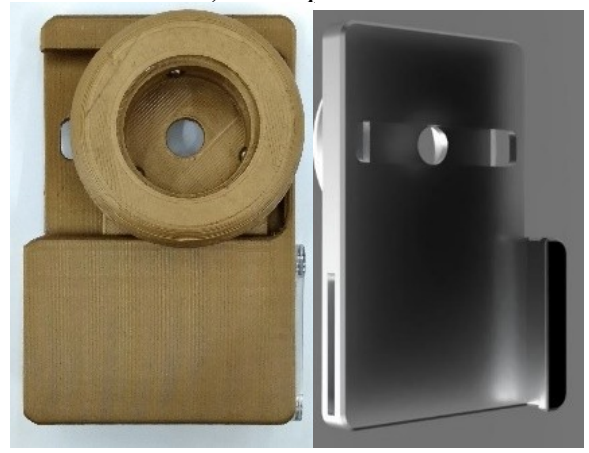

Gambar 4. Eksplorasi desain 3.

Merupakan pengembangan dari explorasi 2 dengan mekanisme slot untuk coupler dan menambahkan ulir pada coupler sehingga dapat dikencangkan ketika sudah mencapai posisi tertentu agar tidak bergerak kenanan dan kekiri.

Kelebihan:

a. Mekanisme penjepit sederhana sehingga mudah di operasikan.

b. Penyesuaian posisi coupler dapat lebih presisi karena mekanisme sliding.

c. Penjepit smartphone berbentuk seperti huruf $\mathrm{C}$ sehingga dapat mencengkram bagian samping dan atas smartphone ketika dipasang.

d. Penjepit yang berada di sisi kanan build-in dengan konektor sehingga tidak ada resiko terlepas ketika penggunaan smartphone dengan orientasi landscape.

Kekuragan:

a. Coupler kokoh pada tempatnya karena memiliki mekanisme ulir sebagai kuncian.

b. Letak coupler berpindah posisi sedikit ketika di dikencangkan/ ulir diputar

c. Hanya cocok untuk smartphone dengan posisi kamera di tengah.

d. Bentuk penjepit membatasi ukuran smartphone yang dapat masuk hanya smartphone dengan tebal $8 \mathrm{~mm}$.

e. Mekanisme enjepit tidak mencengkram dengan kuat sehingga ada kekhawatiran smartphone terjatuh 4) Eksplorasi desain 4

Alternative desain 4 memiliki letak coupler yang fix untuk jenis handphone yang memiliki letak kamera tengah. 


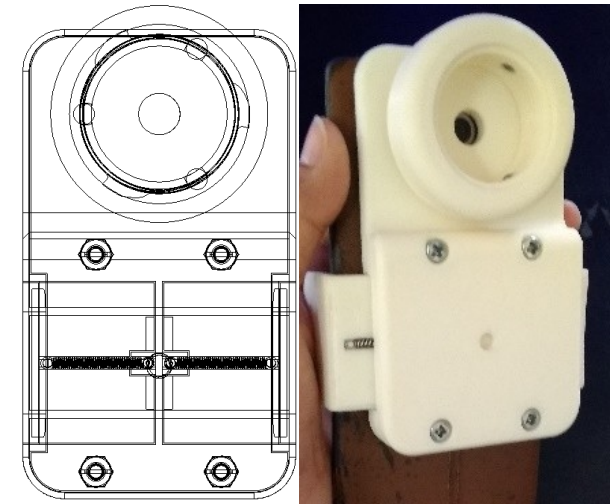

Gambar 5. Eksplorasi desain 4.

Kelebihan:

a. Mekanisme penjepit sederhana sehingga mudah di operasikan.

b. Posisi coupler fix sehingga kokoh dan fit untuk smatphone dengan letak kamera di tengah

c. Penjepit smartphone dilengkapi silicon rubber dan pada bagian samping berbentuk sedikit miring kedalam menambah kerekatan penjepit.

d. Penjepit pada sisi kiri dan kanan dapat di adjust

e. Mekanisme penjepit mencengkram dengan kuat dengan menggunakan extension spring

Kekuragan:

a. Tidak dapat digunakan pada smartphone yang memiliki letak kamera di samping.

5) Eksplorasi desain 5

Alternative desain 5 memiliki letak coupler yang fix untuk jenis handphone yang memiliki letak kamera samping.

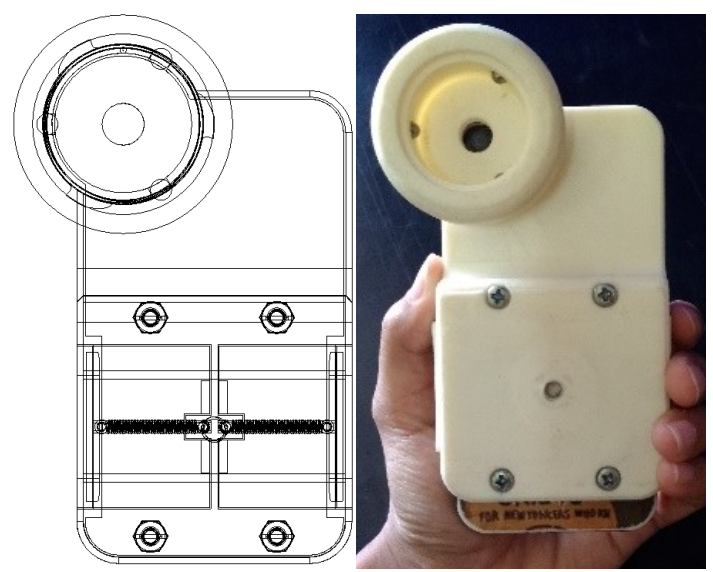

Gambar 6. Eksplorasi desain 3.s
Kelebihan:

a. Mekanisme penjepit sederhana sehingga mudah di operasikan.

b. Posisi coupler fix sehingga kokoh dan fit untuk smatphone dengan letak kamera di tengah

c. Penjepit smartphone dilengkapi silicon rubber dan pada bagian samping berbentuk sedikit miring kedalam menambah kerekatan penjepit.

d. Penjepit pada sisi kiri dan kanan dapat di adjust

e. Mekanisme penjepit mencengkram dengan kuat dengan menggunakan extension spring

Kekuragan:

a. Tidak dapat digunakan pada smartphone yang memiliki letak kamera di tengah.

\section{KESIMPULAN}

Keamanan dan akurasi ukuran sangat mempengaruhi kerja dan hasil dari alat tersebut dalam mendesain endoscope portable. Kebutuhan desain alat sangat dipengaruhi oleh aktifitas pemeriksaan THT yang didapat dari hasil Observasi. Dari 5 eksplorasi dasin yang telah dilakukan dapat disimpulkan eksplorasi ke 4 dan ke 5 memiliki desain yang paling baik, sehingga produksi dapat dilakukan pada kedua desain dengan menyesuaikan jenis smartphone yang dimiliki oleh pengguna. Untuk penelitian selanjutnya diharapkan pengembangan desain bisa memperhatikan bobot produk yang berpengaruh pada kelelahan tangan pengguna.

\section{DAFTAR PUSTAKA}

[1] Kementerian Kesehatan Republik Indonesia, "Profil Kesehatan Indonesia Tahun 2016," Jakarta, 2017.

[2] J. Crump and T. Deutsch, "Exchanging digital video of laryngeal examinations," J. Voice, pp. 13-23, 2004.

[3] V. Papacharalampous, V. Petros, and A. Bibas, "One touch -non PC based- digital recording during otolaryngological endoscopic examination linical Otolaryngology," Clin. Otolaryngol., 2011.

[4] N. Mistry, C. Coulson, and A. George, "Endoscope-i: an innovation in mobile endoscopic technology transforming the delivery of patient care in otolaryngology," 2017.

[5] G. M. Parul, M. Harris, and M. Trucker, "Recording video endoscopy using a portable media device: a novel solution in the age of digital media," New York.

[6] C.-J. Wu, S.-Y. Wu, P.-C. Chen, and Yaoh-Shiang Lin, "An innovative smartphone-based otorhinoendoscope and its application in mobile health and teleotolaryngology," J. Med. Internet Res., p. 71, 2014.

[7] W. Sohn et al., "Using mobile technology to create global point of service endoscopy," J. Endourol., 2013.

[8] J. K. Bae, J. A. Vavilin, S. You, S. H. Kim, J. H. J. Y. Ryu, and W. Jung, "Smartphone-based endoscope system for advanced point-ofcare diagnostics: feasibility study," JMIR mHealth uHealth, p. 99, 2017. 